Original Article (short paper)

\title{
Multivariate linear regression analysis to evaluate multiple-set performance in active and inactive individuals
}

\author{
Frank S. Suzuki ${ }^{1}$, Anderson C. Paulo ${ }^{2}$, Marcos R. R. Pauksnis ${ }^{1}$, Alexandre L. Evangelista ${ }^{1}$, \\ Marcelo M. Kalytczak ${ }^{1}$, Fabiano Politti ${ }^{1}$, Roberta L. Rica ${ }^{3} \oplus$, Andrey J. Serra ${ }^{1}$,

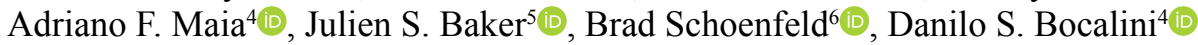 \\ ${ }^{I}$ Universidade Nove de Julho, São Paulo, SP, Brazil, ${ }^{2}$ Universidade Tecnologica Federal do Paraná, UTFPR, Curitiba, \\ PR, Brazil; ${ }^{3}$ Universidade Estácio de Sá, Vitoria, ES, Brazil; ${ }^{4}$ Universidade Federal do Espirito Santo, UFES, \\ Laboratorio de Fisiologia e Bioquimica Experimental, Vitoria, ES, Brazil; ${ }^{5}$ University of the West of Scotland, Institute \\ for Clinical Exercise and Health Science of, Almada Street, Hamilton, UK; ${ }^{6}$ Lehman College, Bronx, United States
}

\begin{abstract}
Aim: To determine how EMG, anthropometric, and psychological factors, and physical activity levels affect isokinetic peak torque performance (IPT) of multiple set exercise sessions. Methods: 20 participants (27 7 years old), classified as active $(\mathrm{A}=10)$ and inactive $(\mathrm{I}=10)$, performed 10x10:40secs of maximal unilateral knee flexions and extensions at 120o.s-1. The IPT, EMG, glucose, LDH, and lactate concentrations and perceptions of pain, effort, recovery. Results: Active volunteers showed higher muscularity ( $52 \pm 5$ vs $47 \pm 4 \mathrm{~cm} ; \mathrm{p}<0.05)$, PTI ( $262 \pm 4$ vs $185 \pm 4 \mathrm{Nm}$; $\mathrm{p}<0.05)$, relative lower drop in performance $(14 \pm 2$ vs $27 \pm 3 \% ; \mathrm{p}<0.05)$, major $\operatorname{MDF}(83 \pm 1$ vs $76 \pm 1 \mathrm{~Hz} ; \mathrm{p}<0.05)$, lower $\log$-Fins5 (-12.9 \pm 0.3 vs $-12.7 \pm 0.3 \mathrm{~Hz} ; \mathrm{p}<0.05)$, smaller subjective perception of effort ( $14.8 \pm 0.3$ vs $17.0 \pm 0.3)$ and higher subjective perception of recovery $(14.2 \pm 0.2$ vs $12.3 \pm 0.3)$. There was a significant interaction between relative fatigue and the number of sets $(\mathrm{F}=6.18 ; \mathrm{p}<0.001)$. Stepwise multiple regressions revealed that subjective perception of recovery best explained the fatigue level generated in the active volunteers [fatigue level $=85.084-5255(\mathrm{SPR})]$ while for body mass was the best determinant for the inactive group [fatigue level $=-21.560+1.828(\mathrm{BMI})$ ]. Conclusion: Data from the present analysis suggest that physically active individuals show higher torque development and a smaller fatigability index when compared to inactive individuals. Among the fatigue models studied, it is possible that alterations in biochemical components, psychophysiological and EMG are not sensitive to the direct influence of the fatigue dynamics protocol, both in active or inactive individuals.
\end{abstract}

Keywords: physical activity levels, isokinetic, electromyography, lactate, lactate dehydrogenase, and psychophysiological scale.

\section{Introduction}

The production and endurance of torque are crucial to sports performance and physical exercise, however, there are several factors (neuromuscular, biochemical, psychological, anthropometric, and training level) may promote influences on performance. Furthermore, the bivariate analysis is frequently used to evaluate the relationship of either neuromuscular, biochemical, psychological, anthropometrical, and training level.

Given the aforementioned information, endurance and torque can be considered a complex and multifactorial phenomenon, and it is important to understand how these factors contribute, together and individually, with respect to alterations in muscular performance. In this way, the electromyography (EMG) has often been used as a tool to predict neuromuscular fatigue ${ }^{1,2}$. This technique provides the ability to detect muscular activity from changes that occur in the amplitude and frequency of an EMG signal ${ }^{1,2}$. Models using biochemical markers are also found in the literature suggestin ${ }^{3}$ that depletion of energy substrates and metabolite accumulation are associated with a reduction in performance.
Psychologically, factors such as subjective perceptions of pain, effort, and recovery are also all relevant measurements used to identify the fatigue process ${ }^{4}$. The quantification of pain has received little attention as a mechanism for recognizing a reduction in performance. Moreover, in intermittent exercises, fatigue could be associated with the effort required to manage muscular imbalance ${ }^{5}$. It has also been reported that a higher subjective perception of effort (SPE) and lower subjective perception of recovery (SPR) are associated with a greater reduction in performance. These perceptions of discomfort would be limiting factors to movement. They also speculate that this could be influenced by an imbalance in the function of a biological system during stressful situations.

Anthropometric factors and training experience also can impact the level of fatigue during exercise. It has been observed that differences in body composition and weight affect strength production and maintenance. In addition, the level of physical activity $^{6,7}$ can influence the muscles ability to contract; individuals who are physically fit tend to be more resistant to fatigue compared to non-fit subjects.

Given the aforementioned information, muscular fatigue can be considered a complex and multifactorial phenomenon, and it is 
important to understand how these factors contribute, together, and individually in decrements of muscular performance. Therefore, the purpose of this study was to investigate via multivariate discriminant analysis how electromyographical, metabolic, anthropometric, psychologic factors and level of physical activity interact during isokinetic peak torque performance.

\section{Methods}

\section{Sample}

Following the approval of the Committee on Ethics in Research with human beings from Universidade São Judas Tadeu (protocol:786.066/2014), 20 healthy males (18 to 36 years old) participated as volunteers in this study. All individuals were properly informed regarding the objectives and procedures and signed a statement of informed consent prior to testing. Exclusion criteria encompassed the following: clinically diagnosed with diabetes mellitus, smokers, and individuals with musculoskeletal disorders and/or cardiovascular alterations. The Adapted International Physical Activity Questionnaire - short form (IPAQ) was used to determine the physical activity level of subjects. Individuals with a minimum of 150 minutes of physical activity per week were considered as active, while subjects below 150 minutes were classified as inactive (insufficiently active) as per WHO (1998). After IPAQ analysis, subjects were separated into two groups: active $(n=10)$ and inactive $(n=10)$.

\section{Experimental approach}

Volunteers visited the laboratory on four separate occasions: on the first day, they signed the TCLE and completed the IPAQ. On the second day, anthropometric data were obtained (height, weight, skinfolds and associated body mass measures). On the third day, they were familiarized to the protocol on the isokinetic dynamometer Biodex System 3 (Biodex, Inc., Shirley, NY).

\section{Evaluated parameters}

\section{Anthropometric parameters}

Height was measured using a Cardio meter stadiometer (WCS model) with a $115 / 120 \mathrm{~cm}$ scale. Weight was obtained with a Filizola electronic scale (Personal Line Model 150) with a 100 grs scale and maximum capacity of $150 \mathrm{~kg}$. Body mass index (BMI) was calculated from the equation weight/ height $^{2}$. Muscular mass index (MMI) was performed according to following equation: $\mathrm{MMI}=\mathrm{CC}-(\pi \mathrm{x}$ skin fold member $)$ the thigh median circumference $(\mathrm{CC}, \mathrm{cm})$.

\section{Isokinetic parameter}

To avoid unwanted body movements during the exercise, belts were fixed on the thigh, pelvic area, and torso. The dynamometer was aligned to the subject's right knee's axis and the arms were crossed across the torso. All subjects performed eight submaximal repetitions, concentric actions for extension and eccentric actions at a speed of $120^{\circ} \mathrm{s}^{-1}$. The Isokinetic Dynamometer was calibrated with the knee joint flexed to $90^{\circ}$. The calibration of the isokinetic dynamometer was performed according to the manufacturer specifications. The fatigue protocol was applied on the fourth day. All tests and experimental processes were executed on the fourth meeting to avoid variations and bias in our data.

Following the familiarization period, subjects performed the fatigue protocol, as outlined in a previous study ${ }^{6}$. Briefly, all subjects performed a short warm-up using the isokinetic dynamometer, which consisted of five repetitions of knee extension in the concentric action and flexion in the eccentric action at a speed of $120^{\circ} \mathrm{s}^{-1}$. Post-warm-up, subjects completed three maximal voluntary isometric contractions (MVIC) with the knee joint flexed at $90^{\circ}$ for five seconds to determine the maximum torque. The workload comprised 10 sets of 10 repetitions at $75 \%$ of MVIC. An angular speed of $120^{\circ} \mathrm{s}^{-1}$ was maintained during the exercise period with a 40 -second rest interval provided between the sets. All test sessions were supervised by the same researcher and all subjects were encouraged verbally during testing.

The isokinetic torque developed by the knee extensors and associated muscles was continuously assessed as outlined previously. During the execution of the fatigue protocol, the highest concentric peak torque in each of the 10 repetitions in each set was recorded, and from this, the percentage decrement score (PDS) was calculated, as proposed by previous study?

$$
\operatorname{PDS}=\frac{1-(\operatorname{Set} 1+\operatorname{Set} 2+\operatorname{Set} 3+\ldots+\text { Set } 10)}{(\text { Best Set x 10) }}
$$

\section{Electromyography parameters}

The surface EMG signal was recorded using an eight-channel module conditioner (bandpass filter at 20-500 H, amplifier gain of 1000 and a common mode rejection ratio $>120 \mathrm{~dB}$ ). All data were acquired and processed using a 16-bit analog to digital converter (EMG System do Brasil Ltda $\AA$ ), with a sampling frequency of $2 \mathrm{kHz}$. The system included active bipolar electrodes with a preamplification gain of 20x. The placement sites for the electrodes were cleaned with a cotton ball soaked in alcohol. Afterward, disposable $10 \mathrm{~mm}$-diameter $\mathrm{Ag} / \mathrm{AgCl}$ surface electrodes (MediTrace $($ ) $)$ were attached to the belly of the muscle with inter-electrode distance center-to-center of $2 \mathrm{~cm}$ in the rectus femoris, vastus medialis oblique and vastus lateralis muscles.

EMG signals for evaluation of muscle fatigue were captured, including the root-mean-square (RMS) value, median frequency (MDF) (FFT computed with a Hamming window processing with $50 \%$ overlap and 1024-point), and the logarithm of the spectral index proposed by Dimitrov $8\left(\log ^{\text {-FInsm5 }}\right)$. All these parameters were calculated for each muscle in each set with ten concentric/ eccentric contractions (total of 10 sets). The values means of each parameter (RMS, MDF, and $\log ^{- \text {-Insm5 }}$ ) obtained in the three muscles (rectus femoris, vastus medialis oblique, and vastus lateralis) were used to verify the electromyographic behavior 
during execution of the fatigue protocol. EMG signals were analyzed using MATLAB software R2010b (The MathWorks Inc., Natick, Massachusetts, E.U.A.).

\section{Biochemistry parameters}

Measures of glucose, lactate and lactate dehydrogenase (LDH) were obtained at rest and at the end of one of the 10 sets comprising the fatigue protocol according to previous publication ${ }^{9,10}$. Glucose plasma concentration was assessed by the enzymatic colorimetric method (GOD-POD), using a commercial "kit" by Accutrend $\AA$. Lactate concentration was determined using a lactimeter model

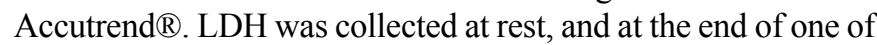
the ten sets of the fatigue protocol. Blood samples were centrifuged at 4,000 RPM for 20 minutes, according to Rodrigues ${ }^{12}$ to analyze LDH. Once the serum was obtained, the analysis was performed with commercial kits for spectrophotometric analysis. Serum was hatched with a citric acid buffer ( $\mathrm{pH} \mathrm{3,4),} \mathrm{sodium} \mathrm{dodecyl}$ sulfate $10 \%$ and thiobarbituric acid $0.6 \%$ at $90^{\circ} \mathrm{C}$ for one hour. The supernatant was then employed for spectrophotometric reading at $532 \mathrm{~nm}$, using malondialdehyde as the pattern. Glucose, lactate, and lactate dehydrogenase concentrations were expressed in $\mathrm{mg} / \mathrm{dl}, \mathrm{m} / \mathrm{Mol}$, respectively.

\section{Subjective parameters}

The subjective perception of effort (SPE) adapted from Borg which graduates from six (no effort) to twenty (maximal effort) points. Subjects rated SPE after performing the $10^{\text {th }}$ repetition of each set. The subjective perception of recovery (SPR) was assessed using the scale of subjective effort proposed by Borg, adapted for recovery by Kenttä \& Hassmén ${ }^{11}$. The scale graduates from six (no recovery at all) to twenty (full recovery). Subjects rated SPR after an interval of the $40 \mathrm{~s}$ between the sets, prior to the beginning of the next repetition. The assessment of subjective perception of pain was recorded using the VAS (Visual Analog Scales). VAS is a 10 $\mathrm{cm}$ line having at the extreme left the descriptive term "No pain" and at the extreme right, the term "Highest pain." Subjects rated subjective perception of pain following completion of the SPE.

\section{Statistical analysis}

All analyses were performed using SPSS software (v 20; IBM, Armonk, NY, USA). D'Agostino-Pearson's test was applied to analyze the normality of the distribution. Student's t-test was used to compare the means between the groups in anthropometric, physical activity levels and SPP variables. ANOVA was used to compare means between groups and sets in the following variables: torque (absolute and relative), metabolic (lactate, glucose, and LDH, neuromuscular (RMS, FDM, and $\log -\mathrm{F}^{\text {Insm5 }}$ ), and psychometrics (SPE scale, pain, and recovery). In cases where the difference was significant, Tukey's post-hoc was employed. An exploratory analysis verified the relationship between the PDS with each variable of anthropometry, psychological, electromyographical, physiological factors and with the physical activity level through Pearson's bi-variate correlation. Following the parameters the significant correlation with PDS was used at stepwise regression model to determine the maintenance of torque peak for the whole sample, for active and inactive individuals. The multi-collinearity among the independent variables was assessed through the inflation factor variation (IFV) and tolerance. The level of significance adopted was $\mathrm{p}<0.05$.

\section{Results}

No differences ( $p>0.05)$ were found on age (Active: $28 \pm 7$, Inactive: $26 \pm 6$; years), body mass (Active: $87 \pm 18$, Inactive: $80 \pm 13 ; \mathrm{kg}$ ), height (Active: $181 \pm 0.07$, Inactive: $174 \pm 0.09$; $\mathrm{cm}$ ), body mass index (Active: $26 \pm 4$, Inactive: $26 \pm 4 ; \mathrm{kg} / \mathrm{cm}^{2}$ ) and muscle mass index (Active: $52 \pm 5$, Inactive: $47 \pm 4 ; \mathrm{cm}$ ), however, differences $(\mathrm{p}=0.001)$ on physical activity level (Active: $657 \pm 267$, Inactive: $121 \pm 36$; $\mathrm{min} /$ week) were found between then.

As illustrated in Figure 1, a significant main effect was noted for physical activity level $(\mathrm{F}=167.14 ; \mathrm{p}<0.001)$ and between sets $(\mathrm{F}=13.05 ; \mathrm{p}<0.05)$. There were no significant interactions between the physical activity level and sets for absolute torque $(\mathrm{F}=1.193 ; \mathrm{p}=0.053)$. Active individuals showed higher absolute torque than the inactive individuals. In relation to the absolute torque produced in the first sets, volunteers began to fatigue $(\mathrm{p}<0.01)$ from the fourth set on.
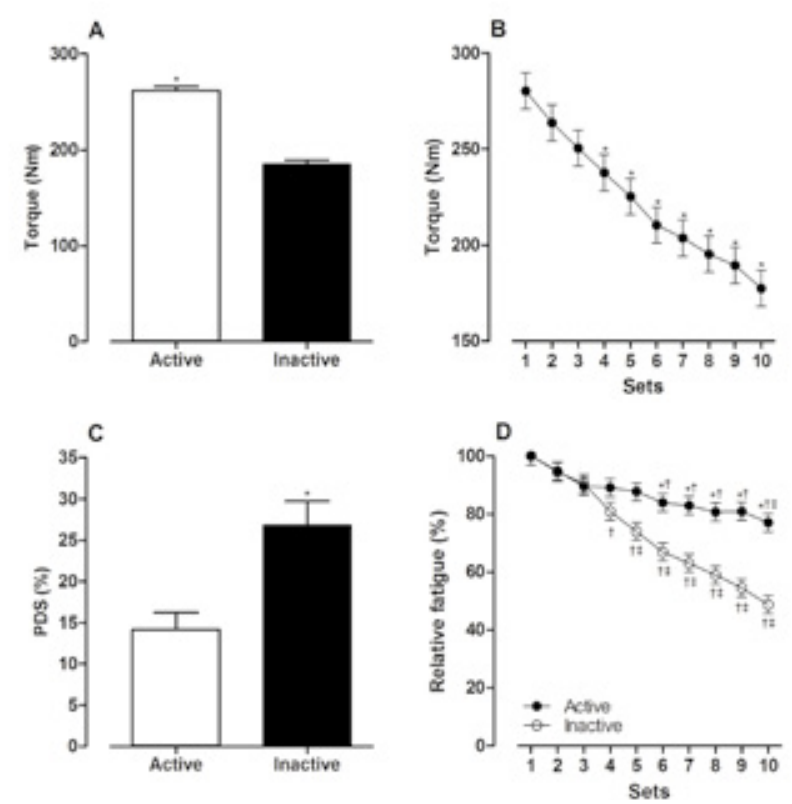

$*$ difference $(\mathrm{p}<0.05)$ among groups. $\dagger$ different $(\mathrm{p}<0.05)$ from the first set. $\$$ different $(\mathrm{p}<0.01)$ from the second set.

Figure 1. Values expressed in mean \pm standard deviation of concentric torque mean and standard deviation corresponding to the first sets between active and inactive groups (A) between sets of 10 repetitions, $(\mathrm{B})$ of the knee extension isokinetic exercise, percentage decrement score and torque concentrics $(\mathrm{C})$ mean and standard error related to do the first set (D) performed by the active and inactive groups, and between sets of 10 repetitions of the knee extension isokinetic exercise. 
There was a significant difference observed between groups for PDS ( $p<0.05)$, and ANOVA showed that there was a significant interaction between groups and sets related to torque in the first set $(\mathrm{F}=6.18 ; \mathrm{p}<0.001)$. The inactive group had a higher decrease in performance both in PDS (Figure $2 \mathrm{~A}$ ) and in torque in the first set (Figure $1 \mathrm{~B}$ ). Figure 1B shows that the inactive group begins to fatigue from the fourth set on. The same observations occur in the active group from the sixth set on.

Figure 2 illustrates the biochemical variable results. There was a major effect for lactate concentration in independent sets regardless of the physical activity level $(\mathrm{F}=58.43 ; \mathrm{p}<0.001)$, and for $\mathrm{LDH}$ $(2.17 ; \mathrm{p}=0.021)$. There was no statistical difference for glucose.
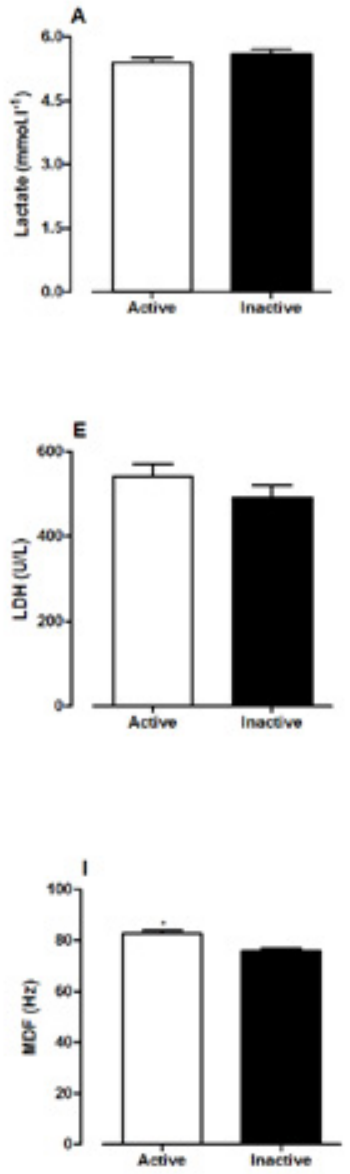
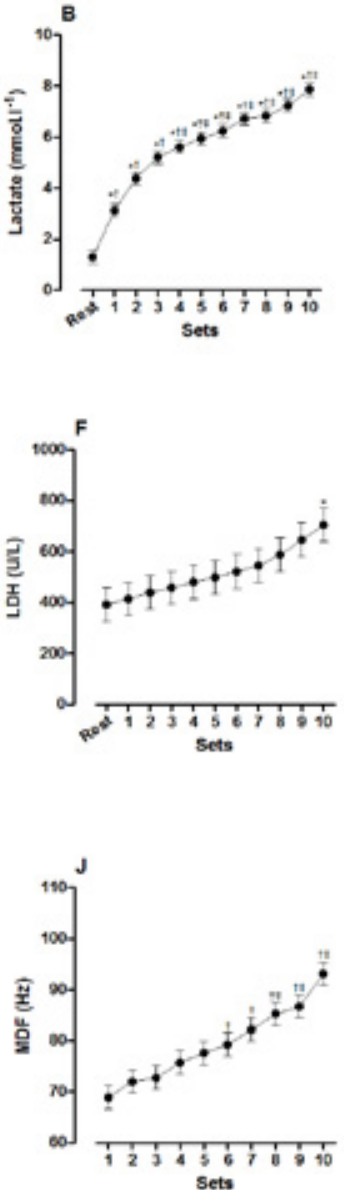
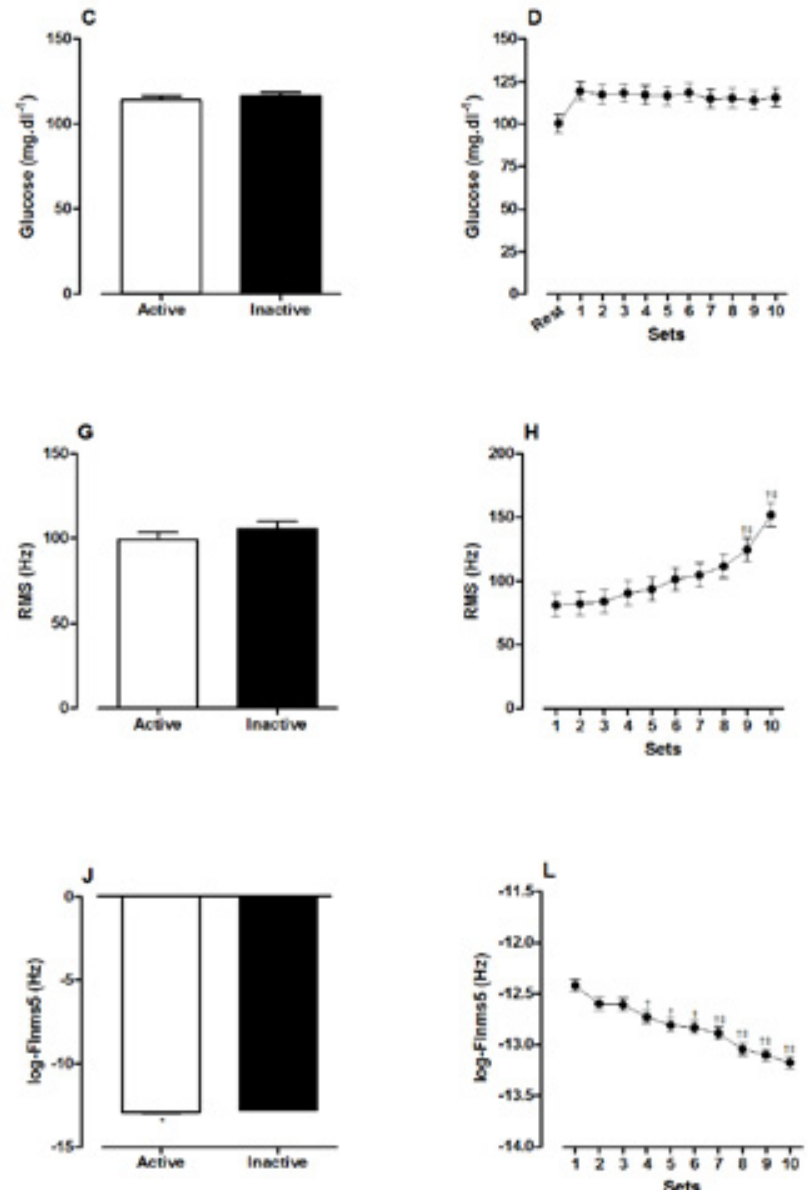

$\dagger$ different $(\mathrm{p}<0.05)$ from the first set of the same group. $\ddagger$ different $(\mathrm{p}<0.05)$ from the second set.

Figure 2. Values expressed in mean \pm standard deviation in pre-exercise (0), and at the end of each set of 10 repetitions in the knee extension isokinetic exercise, between active and inactive subjects. Panels A and B: lactate concentration. Panels C and D: glucose (C and D) Panels E and F: lactate dehydrogenase. Panels G and H: root-mean-square (RMS). Panels I and J: median frequency (MDF). Panels L and M: $\log _{-}{ }^{\text {Finsm5 }}$.

The mean and standard error of the EMG activity of the knee extensors muscles are shown in figure 2. A significant main effect was found between the level of physical activity, regardless the number of sets, for MDF $(\mathrm{F}=22.28 ; \mathrm{p}<0.001)$ and log - FInsm5 $(\mathrm{F}=14,54$ and $\mathrm{p}<0.001)$. The active group produced higher MDF $(82.8 \pm 1,0$ vs $75.9 \pm 1.0)$ and smaller log- FInsm5 $(-12.9 \pm 0.3$ vs $-12.7 \pm 0.3)$ than the inactive group. There was also a major effect between the sets regardless the level of physical activity for RMS $(F=5.64 ; p<0.001)$, MDF $(F=10.7 ; p<0.001)$ and $\log$ - FInsm5 ( $\mathrm{F}=14.53 ; \mathrm{p}<0.001)$.
Figure 3 illustrates the results of psychometric variables. There was a significant main effect among groups in terms of the subjective perception of effort $(F=30.99 ; p<0.001)$ and subjective perception of recovery $(F=31.00 ; p<0.001)$. The inactive group showed a higher subjective perception of effort and a smaller subjective perception of pain. In contrast, there was a major effect between the sets for subjective perception of effort $(\mathrm{F}=6.50 ; \mathrm{p}<0.001)$; recovery $(\mathrm{F}=13.63 ; \mathrm{p}<0.001)$ and pain $(\mathrm{F}=6.83 ; \mathrm{p}<0.001)$. 

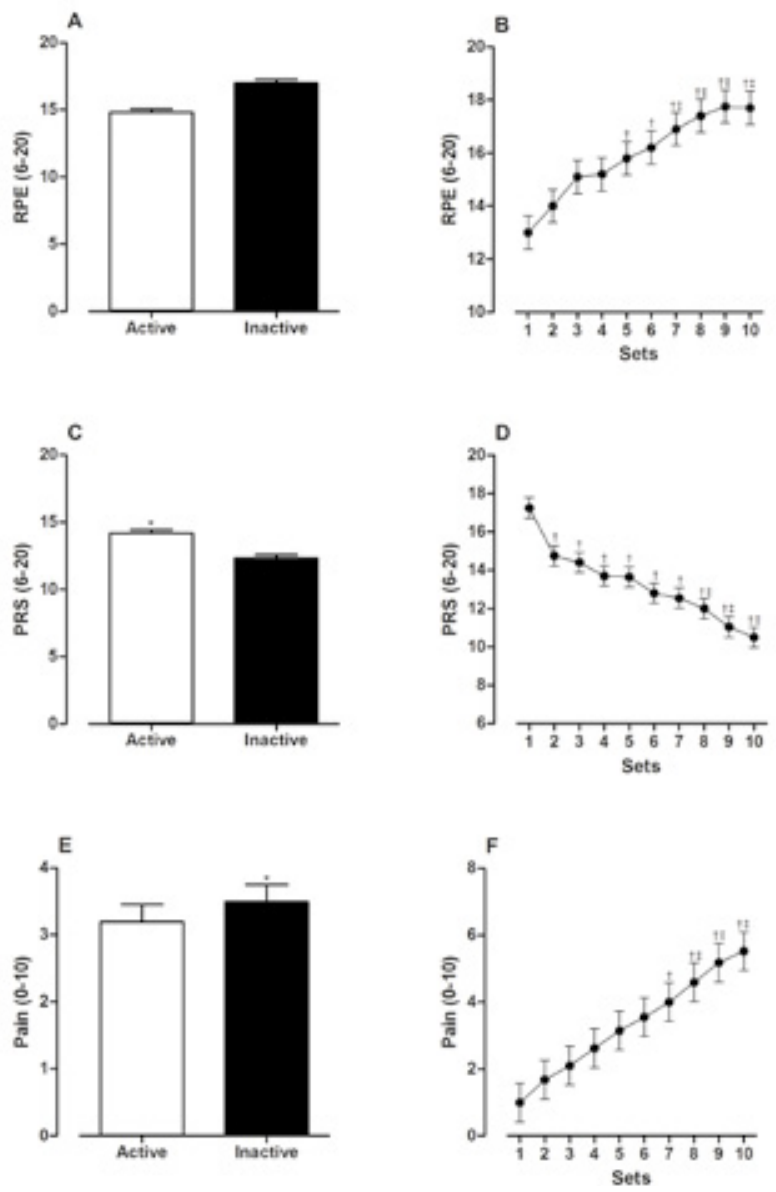

* difference $(\mathrm{p}<0.05)$ among groups. $\dagger$ different $(\mathrm{p}<0.05)$ from the first set. $\ddagger$ different $(\mathrm{p}<0.05)$ from the second set.

Figure 3. Values expressed in mean \pm standard deviation in pre-exercise (0), and at the end of each set of 10 repetitions in the knee extension isokinetic exercise, between active and inactive subjects. Panels A and B: subjective perception of effort (SPE). Panels C and D: subjective perception of recovery (SPR). Panels E and F: pain.

Table 1 displays Pearson's correlation values and the significance level between PDS and the variables theoretically associated to fatigue on peak of torque. Considering all volunteers, there was significant correlation for the level of activity $(\mathrm{r}=-0.641$; $\mathrm{p}=0.001)$, BMI $(\mathrm{r}=0.442 ; \mathrm{p}=0.025)$, PRS $(\mathrm{r}=-0.482 ; \mathrm{p}=0.016)$.
In the active group there was a significant correlation only for the psychometric variables: RPE $(r=0.616 ; \mathrm{p}=0.039)$ e PRS $(r=-0.881 ; p=0.001)$. Finally, in the inactive group there was a significant correlation only in anthropometric variables: Body Mass ( $\mathrm{r}=0.643 ; \mathrm{p}=0.029)$ and $\mathrm{BMI}(\mathrm{r}=0.769 ; \mathrm{p}=0.005)$.

Table 1. Level of association between the percentage decrement score (PDS) of knee extensor muscles' concentric peak of torque with anthropometric, psychometric, metabolic, neural factors and level of physical activity.

\begin{tabular}{|c|c|c|c|c|c|c|c|c|c|c|c|c|c|c|}
\hline & \multirow[b]{2}{*}{$\begin{array}{l}\text { PA } \\
\mathrm{r}(\mathrm{p})\end{array}$} & \multicolumn{4}{|c|}{ Anthropometric } & \multicolumn{3}{|c|}{ Psychometric } & \multicolumn{3}{|c|}{ Metabolic } & \multicolumn{3}{|c|}{ Neurals } \\
\hline & & $\begin{array}{l}\mathrm{BM} \\
\mathrm{r}(\mathrm{p})\end{array}$ & $\begin{array}{l}\mathrm{H} \\
\mathrm{r}(\mathrm{p})\end{array}$ & $\begin{array}{l}\text { BMI } \\
\mathrm{r}(\mathrm{p})\end{array}$ & $\begin{array}{l}\text { MMI } \\
\mathrm{r}(\mathrm{p})\end{array}$ & $\begin{array}{l}\text { SPE } \\
\mathrm{r}(\mathrm{p})\end{array}$ & $\begin{array}{l}\text { SPE } \\
\mathrm{r}(\mathrm{p})\end{array}$ & $\begin{array}{l}\text { Pain } \\
\text { r (p) }\end{array}$ & $\begin{array}{l}\mathrm{Lac} \\
\mathrm{r}(\mathrm{p})\end{array}$ & $\begin{array}{l}\text { Gluc } \\
\mathrm{r}(\mathrm{p})\end{array}$ & $\begin{array}{l}\mathrm{LDH} \\
\mathrm{r}(\mathrm{p})\end{array}$ & $\begin{array}{l}\text { RMS } \\
\text { r (p) }\end{array}$ & $\begin{array}{l}\text { FDM } \\
\mathrm{r}(\mathrm{p})\end{array}$ & $\begin{array}{l}\text { Fins } \\
\mathrm{r}(\mathrm{p})\end{array}$ \\
\hline $\mathrm{PDS}_{\text {all }}$ & $\begin{array}{c}-0.641 \\
(0.001)^{\#}\end{array}$ & $\begin{array}{c}0.316 \\
(0.087)\end{array}$ & $\begin{array}{l}-0.061 \\
(0.400)\end{array}$ & $\begin{array}{c}0.442 \\
(0.025)^{\#}\end{array}$ & $\begin{array}{l}-0.189 \\
(0.212)\end{array}$ & $\begin{array}{c}0.187 \\
(0.215)\end{array}$ & $\begin{array}{c}-0.482 \\
(0.016)^{\#}\end{array}$ & $\begin{array}{c}0.158 \\
(0.252)\end{array}$ & $\begin{array}{l}-0.052 \\
(0.414)\end{array}$ & $\begin{array}{c}0.191 \\
(0.210)\end{array}$ & $\begin{array}{c}-0.195 \\
(0.205)\end{array}$ & $\begin{array}{c}0.048 \\
(0.421)\end{array}$ & $\begin{array}{l}-0.375 \\
(0.052)\end{array}$ & $\begin{array}{c}0.362 \\
(0.058)\end{array}$ \\
\hline PDS $_{\text {active }}$ & --- & $\begin{array}{c}0.007 \\
(0.493)\end{array}$ & $\begin{array}{c}0.443 \\
(0.116)\end{array}$ & $\begin{array}{c}-0.270 \\
(0.241)\end{array}$ & $\begin{array}{l}-0.151 \\
(0.349)\end{array}$ & $\begin{array}{c}0.616 \\
(0.039)^{\#}\end{array}$ & $\begin{array}{c}-0.881 \\
(0.001)^{\#}\end{array}$ & $\begin{array}{c}0.428 \\
(0.125)\end{array}$ & $\begin{array}{l}-0.550 \\
(0.062)\end{array}$ & $\begin{array}{c}0.436 \\
(0.120)\end{array}$ & $\begin{array}{c}-0.024 \\
(0.475)\end{array}$ & $\begin{array}{l}-0.486 \\
(0.092)\end{array}$ & $\begin{array}{c}-0.053 \\
(0.446)\end{array}$ & $\begin{array}{c}0.050 \\
(0.449)\end{array}$ \\
\hline $\mathrm{PDS}_{\text {inactive }}$ & --- & $\begin{array}{c}0.643 \\
(0.029)^{\#}\end{array}$ & $\begin{array}{l}-0.051 \\
(0.444) \\
\end{array}$ & $\begin{array}{c}0.769 \\
(0.005)^{\#} \\
\end{array}$ & $\begin{array}{c}0.309 \\
(0.193)\end{array}$ & $\begin{array}{c}-0.284 \\
(0.213)\end{array}$ & $\begin{array}{c}-0.484 \\
(0.078)\end{array}$ & $\begin{array}{c}0.129 \\
(0.361) \\
\end{array}$ & $\begin{array}{l}-0.005 \\
(0.494) \\
\end{array}$ & $\begin{array}{c}0.205 \\
(0.285) \\
\end{array}$ & $\begin{array}{l}-0.425 \\
(0.110) \\
\end{array}$ & $\begin{array}{l}-0.306 \\
(0.195) \\
\end{array}$ & $\begin{array}{c}0.140 \\
(0.350)\end{array}$ & $\begin{array}{l}-0.058 \\
(0.437) \\
\end{array}$ \\
\hline
\end{tabular}

PDS=Percentage decrement score; $\mathrm{PA}=$ Physical activity; $\mathrm{BM}=$ Body mass; H=Height; $\mathrm{BMI}=$ Body mass index; $\mathrm{MMI}=$ muscle mass index; $\mathrm{RPE}=$ Subjective perception of effort; $\mathrm{SPR}=$ subjective perception of recovery; $\mathrm{Pain}=$ subjective perception of pain; Lac=lactate concentration; Gluc=glucose; $\mathrm{LDH}=$ lactate dehydrogenase; $\mathrm{RMS}=$ signal's mean square root; FDM=median frequency; Fins=spectral index logarithm. \# significant correlation. 
Table 2 demonstrates the equations for $\operatorname{PDS}_{\text {all }}, \operatorname{PDS}_{\text {active }} \mathrm{e}$ $\mathrm{PDS}_{\text {inactive }}$. The model of regression stepwise established that the level of physical activity and body mass had a significant association with $\mathrm{PDS}_{\text {all }}$, as only they were in the equation (Adj
$\left.\mathrm{R}^{2}=0.51 ; \mathrm{p}<0.05\right)$. For $\operatorname{PDS}_{\text {active }}$ only the subjective perception of recovery was a determining factor $\left(\operatorname{Adj} \mathrm{R}^{2}=0.745 ; \mathrm{p}<0.05\right)$, while for $\operatorname{PDS}_{\text {inactive }}$ only BMI $\left(\operatorname{Adj} \mathrm{R}^{2}=0.540 ; \mathrm{p}<0.05\right)$ was a determining factor.

Table 2. Influence of the physical activity level in the prediction of the percentage decrement score (PDS).

\begin{tabular}{lcccc}
\hline Model subjects & Regression equation & Adj R-Sq & N & P \\
\hline All & PDS $=-1.309-13.445\left(\mathrm{PA}^{*}\right)+0.351(\mathrm{BM})$ & 0.51 & 20 & 0.01 \\
Active & $\mathrm{PDS}=85.084-5255(\mathrm{PDS})$ & 0.745 & 10 & 0.002 \\
Inactive & $\mathrm{PDS}=-21.560+1.828(\mathrm{BMI})$ & 0.540 & 10 & 0.009 \\
\hline
\end{tabular}

$*$ Active $=1 ;$ inactive $=0$

\section{Discussion}

This study assessed the influence of various markers of fatigue on isokinetic peak torque in active and inactive individuals. The primary finding of the study was an impairment of peak torque in both groups associated with alterations in electromyographical and psychophysiological signals, with no significant differences in biochemical parameters. Also, considering that fatigue is a complex phenomenon, we developed a predictive equation through multivariate regression analysis, taking into account the parameters analyzed in this study.

Neither biochemical nor electromyographical variables obtained a significant correlation. When groups were isolated, no significant correlation was found in the active group, indicating that the fatigue process is different between active and inactive subjects.

Taking into account the isokinetic peak torque's values, the data of this analysis differs from our previous study on the topic. One hypothesis for these differences could be related to the level of trainability or physical activity level of the active group. The inactive group in this study presented a higher reduction in the isokinetic torque $(-91 \pm 12 \%)$ when compared with a previous study $(46 \pm 5 \%)^{6}$, although it was similar to other studies ${ }^{12}$.

EMG analysis is a popular technique used by researchers to determine muscular fatigue ${ }^{1,2}$. In the present study, a significant difference was found between groups only in the frequency of the signal. Previous studies ${ }^{13,14}$ and have also noted no significant change in EMG signal amplitude (RMS). When comparing fatigue profiles in dynamic exercises through MDF and log-Flnsm5, it was possible to see significant differences between active and inactive individuals. These results show that the EMG's signal frequency is more sensitive to neuromuscular changes. This is also true of the observations recorded during the analysis of fatigue in the vastus medialis, vastus lateralis and biceps femoris muscles in dynamic contractions ${ }^{15}$. These observations could indicate a higher ability to maintain muscle activation, even with peak torque decreasing in physically active individuals, as previously observed ${ }^{6}$.

Subjects in our study showed glycemic alterations resulting in an increase in blood glucose content. The reason for this increase may be attributed to a higher release of glucagon during the exercise, which has been reported previously for high-intensity exercise performance. In regards to lactate concentrations, our findings were similar to other studies using resistance exercise ${ }^{16-17}$. Coswig, Neves, Del Vecchio ${ }^{17}$ assessed trained and untrained individuals in high-intensity leg-press exercises and found the following lactate values: inactive, post $6 \mathrm{mmol}$ and actives, post $8 \mathrm{mmol}$. Using resistance trained practitioners, found a rise in the lactate concentration equivalent to $11.6 \mathrm{mmol}$ after the knee extension exercise, a value similar to the one observed in this study. The rise in the blood lactate concentration has been associated with muscular fatigue, although other studies indicate that lactate does not play a significant role in the process ${ }^{18}$. It, therefore, is better to view lactate concentration as an indicator of exercise intensity, mainly representing the onset of anaerobic metabolism. There is consistent evidence ${ }^{19}$ that intensities of exercise higher than $30 \%$ of $1 \mathrm{RM}$ incite the vascular beds via a vaso-compression mechanism resulting in a significant change of local blood perfusion. At intensities above $85 \%$ of $1 \mathrm{RM}$ the vaso-compressive effect is total.

Alterations in lactate dehydrogenase enzyme concentration is another factor believed to be associated with fatigue and musculoskeletal/metabolic adaptation. Although there were no differences observed between groups in the present study, the increase of enzyme concentrations points to the leakage of the enzyme through the sarcolemma; this has been postulated as a primary marker for muscle injury. Moreover, studies indicate that the LDH enzyme takes part in the metabolism of lactate formation ${ }^{20,21}$, which is in agreement with our findings. This can be seen when we consider the similarity between concentrations of the lactate and lactate dehydrogenase. This indicates that both groups completed the fatigue protocol with similar effort and intensity, and were both subjected to the same metabolic overload.

The perception of effort has been widely used as an indicator of internal loading in different modalities of exercise and physiological conditions ${ }^{22,23}$. Our data support previous findings ${ }^{23}$, with increases in perception of effort proportionally increasing with the intensity of exercise. In addition, our results related to the biochemical indicators confirm that both groups had the same relative load of effort. Perception of pain is an often-used marker in clinical settings ${ }^{24,25}$. Similar to the findings of Abad, Ito, Barroso, Ugrinowitsch, Tricoli ${ }^{26}$, our results demonstrate that trained individuals are more pain tolerant than untrained 
individuals. A considerable increase in pain scores was noted in trained men submitted to strength training sessions at different speeds, and the scores were proportional to increases in the speed of execution. Accordingly, the perception of pain is one of the variables most easily manipulated to promote an increase in training intensity.

A positive correlation has also been observed between physical activity level and perceived recovery. Our results confirm this association. Studies assessing professional athletes submitted to a training program report an improvement in perceived recovery with a corresponding increase in physical condition during different phases of the training period.

Considering that fatigue is complex and multifactorial, with elements of neural, metabolic, psychologic, mechanical and behavioral factors, its analysis previously has been univariate or bi-variate. To our knowledge, this is the first study to analyze fatigue via a multivariate approach, using parameters already outlined in the literature as determinants observed in the process of performance reduction during exercise. Consequently, the isolated interpretation of results in studies of fatigue is not erroneous, although it could limit the understanding of the process, as it ignores the importance of the interaction among the factors determining the fatigue level generated for different individuals and different intensities of exercise.

\section{Conclusion}

Data from the present analysis suggests that physically active individuals show higher torque development and a smaller fatigability index when compared to inactive individuals. Among the fatigue models studied, it is possible that alterations in biochemical components (glucose, lactate and lactate dehydrogenase), psychophysiological (perception of effort and pain) and electromyographic (signal amplitude) are not sensitive to the direct influence of the fatigue dynamics protocol, both in active and inactive individuals. Nonetheless, the electromyographic indicators of fatigue represented by log-Flnms 5 and MDF indexes show they are sensitive to changes in muscular activity between active and inactive individuals during the fatigue protocol. In addition, the understanding of the different determinants of fatigue in an integrated manner during the execution of physical exercise is highly relevant. The equation proposed in this study may be helpful in the experimental investigation of fatigue, as the process is multifactorial in nature.

\section{References}

1. Izquierdo M, Ibañez J, Calbet JAL, González-Izal M, NavarroAmézqueta I, Granados C, et al. Neuromuscular fatigue after resistance training. Int J Sport Med. 2009; 8: 614-623.

2. González-Izal M, Malanda A, Navarro-Amézqueta I, Gorostiaga EM, Mallor F, Ibañez, J, et al. EMG spectral indices and muscle power fatigue during dynamic contractions. J Electromy Kinesiol. 2010; 20: 233-240.
3. Bertuzzi, MCM, Franchini, E, and Kiss, MPD. Acute muscle fatigue: a brief review of the physiological systems and their possible relationships. Motriz: J. Phys. 2004; 10: 45-54.

4. Suzuki S, Sato T, Maeda A, Takahashi Y. Program design based on a mathematical model using rating of perceived exertion for an elite Japanese sprinter: a case study. J Strengt Cond Res. 2006; 1: 36-426.

5. Paulo AC, Roschel H, Ugrinowitsch C, Kobal R, Tricoli V. influence of different resistance exercise loading schemes on mechanical power output in work to rest ratio-equated and-nonequated conditions. J Strengt Cond Res. 2012; 5: 1308-1312.

6. Suzuki FS, Martins MK, Sita D, Figueira Junior AJ, Kilgore L, Backer JS, et al. Impact of physical activity level on maximal strength after isokinetic fatigue protocol in college students. Braz J Spor Med. 2016; 2: 97-100.

7. Girrad O, Mendez-Villanueva A, Bishop D. Repeated-Sprint Ability - Part I: contributing to fatigue. Sport Med. 2001; 8: 673-694.

8. Dimitrov GV, Arabadzhiev TI, Mileva KN, Bowtell JL, Crichton N, Dimitrova, NA. Muscle fatigue during dynamic contractions assessed by new spectral indices. Med Sci Sports Exerc. 2006; 38: 1971-1979.

9. Paunksnis MR, Evangelista AL, Teixeira CVLS, João GA, Pitta $\mathrm{RM}$, Alonso AC, et al. Metabolic and hormonal responses to different resistance training systems in elderly men. Aging Male. 2017; 21(2):106-110.

10. Rodrigues BM, Dantas E, Salles BF, Miranda H, Koch AJ, Willardson JM. Creatine Kinase and Lactate Dehydrogenase Responses After Upper-Body Resistance Exercise With Different Rest Intervals. J Strengt Cond Res. 2010; 24(6): 1657-1662.

11. Kentta G, Hassmen P. Overtraining and recovery - a conceptual model. Sport Med. 1998; 26(1): 1-16.

12. Klass M, Baudry S, Duchateau J. Voluntary activation during maximal contraction withadvancing age: a brief review. Europ J Appl Physiol. 2007; 100(5): 543-551.

13. Bogdanis GC. Effects of physical activity and inactivity on muscle fatigue. Front Physiol. 2012; 3(142): 1-15.

14. Silva CR, Geres BS, Kuriki HU, Negrao Filho RF, Alves N, Azevedo, FM. Analysis of reliability of EMG signal frequency domain parameters used in the characterization of localized muscle fatigue. Motriz: J. Phys. 2012; 18(3): 456-464.

15. Gonzalez-Izal MA, Malanda I, Navarro-Amezqueta EM, Gorostiaga F, Mallo J, Ibanez M, et al. EMG spectral indices and muscle power fatigue during dynamic contractions. J Electromy Kinesiol. 2010; 20: $233-240$.

16. Porto FM, Orsatti FL, Santos MDB, Burini RC. Impact of exercising muscles to exhaustion on blood markers in weight-training. Rev Bras Cineantropom Desempenho Hum. 2008; 10(3): 230-236.

17. Coswig VS, Neves AHS, Del Vecchio FB. Effects of duration practice in biochemical, hormonal and hematological parameters of people who practice brazilian jiu-jitsu. Rev Andaluza Med Deport. 2013; 1: 17-23.

18. Macedo DV, Lazarin FL, Silva FOC, Tessuti LS, Hohl R. Is lactate production to muscular fatigue? A pedagogical proposition using empirical facts. Advanc Physiol Educ. 2009; 33: 302-307.

19. Yasuda T, Fukumura K, Fukuda T, Iida H, Imuta H. Effects of low- intensity, elastic band resistance exercise combined with blood flow restriction on muscle activation. Scand J Med Sci Sport. 2012; 1: 55-61. 
20. Brancaccio, P, Limongelli, FM, Maffulli N. Monitoring of serum enzymes in sport. British J Sport Med. 2006; 40: 96-97.

21. Schroder H, Navarro E, Mora J, Galiano D, Tramullas A. Effects of $\alpha$-tocopherol, Bcarotene and ascorbic acid on oxidative, hormonal and enzymatic exercise stress markers in habitual training activity of professional basketball players. Eur J Nut. $2001 ; 40: 178-184$

22. Monteiro W, Simao R, Farinatti PT. Manipulação na ordem dos exercicios e sua influencia sobre numero de repeticoes e percepcao subjetiva de esforco em mulheres treinadas. Braz J Sport Med. 2005; 11(2): 146-150.

23. Wallace LK, Coutts AJ, Bell J, Simpson N, Slattery KM. Using session-RPE to monitor training loads in swimmers. J Strengt Cond Res. 2008; 30(6): 72-76,.

24. Maior AS, Menuci T, Soares V, Souza LR, Gribov M, Simão R. Variation of the training overload in the behavior of the muscular force and subjective perception of pain in sedentary female. Med. 2008; 2: 168-176.

25. Ellwanger RB, Brentano MA, Fernando L, Kruel M, Hoc P. The effect of different velocities of strength training in indirect markers of muscle damage. Rev Bras Educ Fisic Esport. 2007; 12(4): 259-270.
26. Abad CCC, Ito LT, Barroso R, Ugrinowitsch C, Tricoli V. Effect of classical massage on subjective perceived soreness, edema, range of motion and maximum strength after delayed onset muscle soreness induced by exercise. Braz J Sport Med. 2010; 1: 36-40.

\section{Corresponding author}

Danilo Sales Bocalini

Universidade Federal do Espirito Santo, Goiabeiras, Vitoria, Brazil Av. Fernando Ferrari, 514 - Goiabeiras, Vitória - ES, 29060-220

Email: bocaliniht@hotmail.com

Manuscript received on June 18, 2018

Manuscript accepted on September 26, 2018

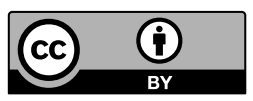

Motriz. The Journal of Physical Education. UNESP. Rio Claro, SP, Brazil - eISSN: 1980-6574 - under a license Creative Commons - Version 4.0 